\title{
Preparation and evaluation of ofloxacin-loaded palmitic acid solid lipid nanoparticles
}

\author{
This article was published in the following Dove Press journal: \\ International Journal of Nanomedicine \\ 14 March 201 I \\ Number of times this article has been viewed
}

\section{Shuyu Xie \\ Luyan Zhu \\ Zhao Dong \\ Yan Wang \\ Xiaofang Wang \\ WenZhong Zhou}

Department of Preventive Veterinary

Medicine, College of Veterinary

Medicine, China Agricultural

University, Beijing, People's

Republic of China
Correspondence: WenZhong Zhou Department of Preventive Veterinary Medicine, College of Veterinary Medicine, China Agricultural University, 2 Yuanmingyuan Road West, Beijing 100193, People's Republic of China Tel +86 I0-62734702

$\mathrm{Fax}+86$ 10-62734840

Email zhouwz@cau.edu.cn
Abstract: The purpose of this study was to use solid lipid nanoparticles (SLN) to improve the pharmacological activity of ofloxacin. Ofloxacin-loaded SLN were prepared using palmitic acid as lipid matrix and poly vinyl alcohol (PVA) as emulsifier by a hot homogenization and ultrasonication method. The physicochemical characteristics of SLN were investigated by optical microscope, scanning electron microscopy, and photon correlation spectroscopy. Pharmacokinetics was studied after oral administration in mice. In vitro antibacterial activity and in vivo antibacterial efficacy of the SLN were investigated using minimal inhibitory concentrations (MIC) and a mouse protection model. The results demonstrated that the encapsulation efficiency, loading capacity, diameter, polydispersivity index, and zeta potential of the nanoparticles were $41.36 \% \pm 1.50 \%, 4.40 \% \pm 0.16 \%, 156.33 \pm 7.51 \mathrm{~nm}, 0.26 \pm 0.04$, and $-22.70 \pm 1.40 \mathrm{mv}$, respectively. The SLN showed sustained release and enhanced antibacterial activity in vitro. Pharmacokinetic results demonstrated that SLN increased the bioavailability of ofloxacin by 2.27-fold, and extended the mean residence time of the drug from 10.50 to 43.44 hours. Single oral administrations of ofloxacin-loaded nanoparticles at 3 drug doses, $5 \mathrm{mg} / \mathrm{kg}, 10 \mathrm{mg} / \mathrm{kg}$, and $20 \mathrm{mg} / \mathrm{kg}$, all produced higher survival rates of lethal infected mice compared with native ofloxacin. These results indicate that SLN might be a promising delivery system to enhance the pharmacological activity of ofloxacin.

Keywords: ofloxacin, pharmacological activity, solid lipid nanoparticles, antibacterial activity

\section{Introduction}

Ofloxacin is one of the most widely available fluoroquinolone antibiotics. It has potent bactericidal activity against a broad range of clinically relevant Gram-negative and Gram-positive pathogens, as well as Mycoplasma, Chlamydia, and Legionella ${ }^{1-4}$ This antibiotic has been effectively used to treat a variety of bacterial infections, including those of the respiratory tract, skin structure, bone, gastrointestinal tract, and urinary tract, and bacterial prostatitis, sexually transmitted diseases, and wound and surgical infections. ${ }^{1,3}$ Ofloxacin is normally administered orally. ${ }^{3}$

However, the poor aqueous solubility of ofloxacin gives rise to difficulties in the design of pharmaceutical formulations and leads to variable bioavailability. ${ }^{5,6}$ In addition, almost all of the oral ofloxacin formulations are available only as conventional, immediate-release tablets that require twice daily administration for consecutive days or weeks. ${ }^{7-9}$ The repeated oral doses of ofloxacin over long time could result in nervous system and gastrointestinal system disorders. ${ }^{10,11}$ Efforts have been made to develop alternative formulations of ofloxacin to improve therapeutic efficacy and reduce frequency of administration. ${ }^{12-16}$ Ofloxacin-loaded liposomes 
produced higher intracellular drug concentrations and antimicrobial activities. ${ }^{15}$ The gastroretentive tablet and sustained-release pellet have been developed for once-daily administration. $^{13,14}$

Solid lipid nanoparticles (SLN) have attracted increasing attention in pharmaceutics as an alternative dosage form to liposomes and polymeric nanoparticles. SLN possess good tolerability and stability, scaling-up feasibility, and the ability to incorporate hydrophobic/hydrophilic drugs. ${ }^{17-19}$ The incorporation of poorly soluble drugs into SLN can enhance gastrointestinal solubilization, absorption, and bioavailability of drug. ${ }^{20,21}$ Pandey et al demonstrated that 5 oral doses of antitubercular drug-loaded SLN administered every 10 days provided an equivalent therapeutic benefit to 46 daily doses of oral free drugs. ${ }^{22}$ Our research showed that SLN could significantly extend systemic circulation times, enhance antibacterial activity in vitro, increase the bioavailability, reduce the dose and frequency of administration, and decrease side effects of tilmicosinin. ${ }^{23,24}$ Fatty acid-SLN increased the bioavailability and extended the mean residence time of enrofloxacin by several-fold. ${ }^{25}$

In this study, ofloxacin-loaded palmitic acid SLN was prepared using palmitic acid as lipid matrix and poly vinyl alcohol (PVA) as emulsifier by a hot homogenization and ultrasonication method. The palmitic acid has been adopted to prepare SLN. PVA is the most commonly used emulsifier in the formulation of nanoparticles due to its excellent mechanical strength, biocompatibility and nontoxicity, and has been approved by the US Food and Drug Administration for medical and food applications. ${ }^{26}$ The hot homogenization and ultrasonication method was feasible to prepare poor water solubility drug-loaded SLN ${ }^{24,25,27}$ The physicochemical properties and pharmacokinetics of the SLN were investigated and the antibacterial activities of ofloxacin-loaded SLN against Staphylococcus aureus were evaluated in vitro and in vivo.

\section{Materials and methods Materials}

Palmitic acid was bought from Shanghai Sangon Biological Engineering Technology \& Services Co., Ltd. (Shanghai, China). Ofloxacin was obtained from Wuhan Konglong Century Technology Development Co., Ltd. (Wuhan, China). PVA was purchased from Sigma-Aldrich (St. Louis, MO, USA). Ofloxacin reference standard was available from China Institute of Veterinary Drug Control (Beijing, China). Methyl alcohol used for high performance liquid chromatography (HPLC) was of liquid chromatography (LC) grade and was purchased from Tedia
Company, Inc (USA). The water for HPLC was prepared with a Milli-Q system (Millipore, Bedford, MA). Citric acid was obtained from Sinopharm Chemical Reagent Co., Ltd. (Beijing, China). Other chemicals and reagents not specified in the text were of analytical grade or equivalent.

\section{Animals and bacteria}

Kunming species mice (male, $30 \pm 1 \mathrm{~g}$ ) were obtained from the Medical Animal Test Center of Peking University, China. The animals were housed at room temperature under natural day and night cycles with free access to water and normal mice food (Beijing Keao Xieli Co., Ltd., China). They were kept for at least 1 week before use. After experiments, all the surviving mice were sacrificed by cervical dislocation. All experimental protocols concerning the handling of mice were in accordance with the requirements of the Institutional Animal Care and Use Committee at China Agricultural University.

S. aureus (CCVCC2248) was available from China Institute of Veterinary Drug Control (Beijing, China). Bacteria were streaked from glycerol-frozen stocks onto agar plates and incubated overnight at $37^{\circ} \mathrm{C}$. A single bacterial colony from the fresh plates was inoculated in the Mueller-Hinton broth $(\mathrm{MH})$ and grown at $37^{\circ} \mathrm{C}$ in a shaking incubator at $230 \mathrm{rpm}$ to an $\mathrm{OD}_{600}$ of 0.6 , which corresponds to $\sim 8 \times 10^{8}$ colony forming units $(\mathrm{cfu}) / \mathrm{mL}$, confirmed by plating serial dilutions. For in vitro study, the bacteria were diluted in broth. For in vivo study, the bacteria were collected by centrifugation at $4000 \mathrm{rpm}$ (Centrifuge $5810 \mathrm{R}$; Eppendorf, Germany) for 10 minutes at $4^{\circ} \mathrm{C}$ and resuspended in sterile saline at different concentrations.

\section{Preparation of ofloxacin-loaded SLN}

Nanoparticles were prepared by a hot homogenization and ultrasonication method. Palmitic acid (4.5 g) and ofloxacin $(0.5 \mathrm{~g})$ were added in a $100 \mathrm{~mL}$ beaker and heated to $150^{\circ} \mathrm{C}$ by a homeothermia magnetic stirrer (Shanghai Zhenrong Scientific Instrument Co., Ltd., China). After the drug was dissolved in the melted palmitic acid, the oil phase was poured into $120 \mathrm{~mL}$ of boiling 1\% PVA solution under magnetic stirring at $150 \mathrm{rpm}$ for 3 minutes to form an oil in water emulsion, and then further sonicated for 5 minutes $(\mathrm{VC} \times 750$ Vibra-CellTM, Sonics and Materials, Inc., Newtown, CT, USA, using the $13 \mathrm{~mm}$ microprobe with amplitude $35 \%$ ) to form a nanoemulsion. The hot nanoemulsion was quickly poured into $400 \mathrm{~mL}$ cold water to obtain a nanoparticle suspension. The nanoparticles were collected by centrifugation at $12000 \mathrm{rpm}$ (Centrifuge $5810 \mathrm{R}$; 
Eppendorf, Germany) for 60 minutes at $4^{\circ} \mathrm{C}$, and washed 3 times with distilled water. The SLN were re-suspended in $120 \mathrm{~mL}$ distilled water and lyophilized for 48 hours (LGJ-12 Freeze Dryer; Beijing Songyuanhuaxing Science Technology Development Co., Ltd., China). The control SLN was prepared similarly without adding ofloxacin.

\section{Microscopic analysis}

Briefly, $5 \mathrm{mg}$ freeze-dried SLN was suspended in $1 \mathrm{~mL}$ double distilled water and two micro liters of the suspension were placed on a microscope slide surface. Photomicrographs of the SLN were taken using an inverted optical microscope (Olympus 1X71, Olympus, Japan).

\section{Scanning electron microscopy (SEM) of nanoparticles}

The morphology of nanoparticles was investigated by SEM (SE S-3400N; HITACHI, Japan). Briefly, $10 \mathrm{mg}$ freeze-dried SLN was suspended in $1 \mathrm{~mL}$ distilled water and $2 \mu \mathrm{L}$ of the suspension was placed on a glass surface. After oven-drying, the samples were coated with gold using an Ion Sputter and examined at an accelerating voltage of $20 \mathrm{kV}$.

\section{Determination of loading capacity and encapsulation efficiency}

To determine SLN incorporation capacity, $10 \mathrm{mg}$ freezedried SLN was dissolved in chloroform and the solution was analyzed directly at $287.8 \mathrm{~nm}$ using a UV spectrophotometer (U-1800, Hitachi Tech Co., Ltd., Japan). The control SLN prepared without drug were treated similarly and used as control for the measurements. The assay was repeated three times using different samples from independent preparations. Loading capacity (LC) and encapsulation efficiency (EE) are defined as follows: ${ }^{27}$

$$
\begin{aligned}
\mathrm{LC}= & {[(\text { weight of ofloxacin in SLN }) /} \\
& (\text { weight of SLN })] \times 100 \% \\
\mathrm{EE}= & {[(\text { weight of ofloxacin in SLN }) /} \\
& (\text { weight of ofloxacin added })] \times 100 \%
\end{aligned}
$$

\section{Determination of particle size, polydispersity index, and zeta potential}

The size, polydispersity index (PDI), and zeta potential of ofloxacin-loaded SLN were measured by photon correlation spectroscopy (PCS) using Zetasizer Nano ZS90 (Malvern Instruments, $\mathrm{UK}$ ) at $25^{\circ} \mathrm{C}$. The samples were suspended in distilled water by ultrasonication for 5 seconds at $0^{\circ} \mathrm{C}$ to remove air bubbles and break up agglomerates. The concentration of sample was $2.7 \mathrm{mg} / \mathrm{mL}$ for particle size and PDI, $0.3 \mathrm{mg} / \mathrm{mL}$ for zeta potential determinations to get optimum kilo counts per second (kcps) of 20 to 400 for measurements.

\section{Determination of residual PVA}

The amount of PVA associated with ofloxacin-loaded SLN was determined by a colorimetric method described previously. ${ }^{27}$ Briefly, $8 \mathrm{mg}$ lyophilized SLN was treated with $2 \mathrm{~mL} 0.5 \mathrm{M} \mathrm{NaOH}$ for 15 minutes at $60^{\circ} \mathrm{C}$. Each sample was neutralized with $900 \mu \mathrm{l} 1 \mathrm{M} \mathrm{HCl}$ and the volume was adjusted to $5 \mathrm{~mL}$ with distilled water. The solution was filtered with $0.22 \mu \mathrm{m}$ filters and mixed with $3 \mathrm{~mL} 0.65 \mathrm{M}$ boric acid solution, $0.5 \mathrm{~mL} \mathrm{I}_{2} / \mathrm{KI}(0.05 \mathrm{M} / 0.15 \mathrm{M})$ solution and $1.5 \mathrm{~mL}$ distilled water. Following incubation at room temperature for 15 minutes, the absorbance was measured at $690 \mathrm{~nm}$ using a UV spectrophotometer (U-1800, Hitachi, Japan). A standard plot of PVA was done under identical conditions.

\section{In vitro release studies}

Ofloxacin-loaded SLN (10 mg) or native ofloxacin $(400 \mu \mathrm{g})$ were suspended or dissolved in $2 \mathrm{~mL} 0.1 \mathrm{M}$ sterile hydrochloric acid (donor solution) in a dialysis bag and dialyzed against $45 \mathrm{~mL} 0.1 \mathrm{M}$ sterile hydrochloric acid (receiver solution) in a $50 \mathrm{~mL}$ tube at $37^{\circ} \mathrm{C}$ under magnetic stirring at $100 \mathrm{rpm}$. To determine the ofloxacin amount diffused through the dialysis bag, samples $(2 \mathrm{~mL})$ were taken from the receiver solution and the same amount of fresh $0.1 \mathrm{M}$ sterile hydrochloric acid was added to keep a constant volume at fixed time points. The sink conditions were maintained for release study. Ofloxacin in the samples was measured spectrophotometrically at $287.8 \mathrm{~nm}$ using a UV spectrophotometer (U-1800, Hitachi Tech Co., Ltd., Japan). The control nanoparticles without ofloxacin were treated similarly and used as blanks for the measurements.

\section{Antibacterial activity studies}

Minimal inhibitory concentrations (MIC) were determined by the Clinical and Laboratory Standards Institute (CLSI) micro-dilution method. ${ }^{28} S$. aureus $(100 \mu \mathrm{L}$, concentration $\sim 1 \times 10^{6} \mathrm{cfu} / \mathrm{mL}$ ) was added to each well of a 96-well plate containing $100 \mu \mathrm{L}$ of ofloxacin-loaded SLN suspension in $\mathrm{MH}$. The final bacterium concentration in individual wells was $\sim 5 \times 10^{5} \mathrm{cfu} / \mathrm{mL}$. The final ofloxacin concentrations were $0.05,0.1,0.2,0.3,0.4,0.5,0.6,0.7$, and $0.8 \mu \mathrm{g} / \mathrm{mL}$. The plate was incubated at $37^{\circ} \mathrm{C}$ and the MIC was determined as the lowest concentration with clear wells at 12, 24, 36, and 48 hours. The MIC of native and released ofloxacin was measured in the same way. 


\section{Pharmacokinetics study}

Before initiation of the experiment, 50 mice were randomly divided into 10 groups with 5 animals in each group. Then $0.3 \mathrm{mg}$ naked ofloxacin dissolved in $200 \mu \mathrm{L}$ sterile distilled water or $6.8 \mathrm{mg}$ ofloxacin-SLN containing $0.3 \mathrm{mg}$ ofloxacin suspended in $200 \mu \mathrm{L}$ sterile distilled water was administered orally to each mouse. At different time points $(0.08,0.17$, $0.33,0.5,1,2,4,8,12,18,24,36,48,72,96,120$ hours) post-administration, blood samples were taken from the tail vein and the drug levels in the plasma were assayed. For each treatment, 5 groups of mice were contained and the blood samples $(500 \mu \mathrm{L})$ were collected in turn from 5 groups over the observation period because of the limited blood volume that could be safely collected from each mouse.

\section{HPLC assay}

Ofloxacin concentrations in plasma were determined by HPLC. The method consists of reverse-phase chromatography and fluorimetric detection. Chromatographic conditions were as follows: excitation wavelength, 360 ; emission wavelength, 465; column, VP-ODS $250 \mathrm{~mm} \times 4.6 \mathrm{~mm}$ (Shimadzu Coperation, Kyoto, Japan); mobile phase, $0.05 \mathrm{~mol} / \mathrm{L}$ citric acid ( $\mathrm{pH}$ of the aqueous phase was adjusted by triethylamine to 3.5$)$ /acetonitrile $(85 / 15$, $\mathrm{v} / \mathrm{v}$ ); flow rate, $1 \mathrm{~mL} / \mathrm{min}$; column temperature, $25^{\circ} \mathrm{C}$. Sample extracts were prepared by mixing $100 \mu \mathrm{L}$ plasma with $200 \mu \mathrm{L}$ mixture of methyl alcohol and acetonitrile $(1 / 1 \mathrm{v} / \mathrm{v})$. The mixtures were vortexed for 3 minutes to allow complete mixing, followed by centrifugation at $14000 \mathrm{rpm}$ (Sigma 1-14; Sartorius, Germany) for 25 minutes. Then $50 \mu \mathrm{L}$ supernatant was used for HPLC analysis. The plasma concentration of ofloxacin was found to be linear over the range 0.06 to $4 \mu \mathrm{g} / \mathrm{mL}$. The correlation coefficient was 0.9996 . The lowest value of the standard curve $(0.056 \mu \mathrm{g} / \mathrm{mL})$ was taken as the limit of quantitation. The recovery for the plasma ofloxacin from 3 concentrations $(0.1,1$, and $4 \mu \mathrm{g} / \mathrm{mL})$ was $80.13 \% \pm 5.14 \%$, $87.37 \% \pm 3.51 \%$, and $89.25 \% \pm 2.19 \%$, respectively. The relative standard deviations (RSD) of accuracy and precision for 3 different plasma concentrations of ofloxacin $(0.1,1$, and $4 \mu \mathrm{g} / \mathrm{mL})$ were $5.38 \%, 2.99 \%$, and $1.86 \%$ for intra-day analysis, and $4.58 \%, 3.03 \%$, and $1.40 \%$ for interday analysis, respectively.

\section{Pharmacokinetic analysis}

The data of plasma ofloxacin concentration-time were analyzed based on noncompartmental pharmacokinetics using the PK Solutions 2.0 (Ashland, OH, USA) computer software.

\section{In vivo efficacy studies}

Determination of the minimum lethal dose: bacteria $(0.3 \mathrm{~mL}$ at concentrations of $3 \times 10^{9}, 6 \times 10^{9}$, and $12 \times 10^{9} \mathrm{cfu} / \mathrm{mL}$ ) were injected intraperitoneally into each mouse of 3 groups with 10 mice in each group. Mice deaths were observed every 12 hours over a 72-hour period to determine the inoculum size of lethal infection.

Drug treatment and efficacy evaluation: 70 mice were randomly divided into 7 groups with 10 animals in each group. Each mouse was injected intraperitoneally with the minimum lethal infection inoculum size of bacteria. Infected mice were orally administrated with a single dose of ofloxacinloaded SLN (suspended in $200 \mu \mathrm{L}$ sterile distilled water) or native ofloxacin (dissolved in $200 \mu \mathrm{L}$ sterile distilled water) 2 hours post-infection. The dose of ofloxacin was $5 \mathrm{mg} / \mathrm{kg}$, $10 \mathrm{mg} / \mathrm{kg}$, and $20 \mathrm{mg} / \mathrm{kg}$, respectively. A separate group of control animals was administrated orally with $200 \mu \mathrm{L}$ sterile water. Animals were observed every 12 hours and deaths were recorded over a 120-hour period.

\section{Statistical methods}

The data on loading capacity, encapsulation efficiency, particle size, and PDI, as well as zeta potential and pharmacokinetic parameters were analyzed using one-way ANOVA. Significance was evaluated at a $P$ value of 0.05 . Statistical analysis was performed using Microsoft Excel (2003).

\section{Results}

\section{Physicochemical characteristics of SLN}

Photographs showed that SLN were spherical (Figure 1B), well dispersed with good particle size distributions (Figure 1A). Further PCS analysis demonstrated that the

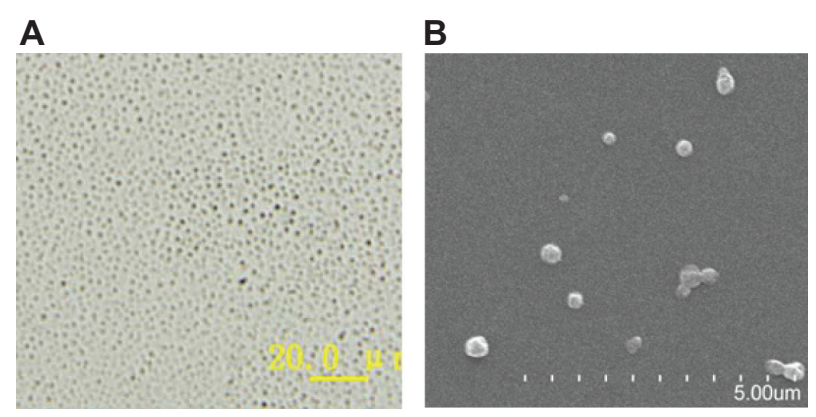

Figure I Photographs of ofloxacin-loaded solid lipid nanoparticles: A) optical microscope (magnification $\times 400$ ); B) scanning electron microscope. 
Table I Physicochemical characteristics of ofloxacin-loaded solid lipid nanoparticles (mean $\pm S D, n=3$ )

\begin{tabular}{llllll}
\hline EE (\%) & LC (\%) & MD (nm) & PDI & ZP (mv) & RP (\%) \\
\hline $41.36 \pm 1.50$ & $4.40 \pm 0.16$ & $156.33 \pm 7.5 \mathrm{I}$ & $0.26 \pm 0.04$ & $-22.70 \pm 1.40$ & $1.28 \pm 0.12$ \\
\hline
\end{tabular}

Abbreviations: EE, encapsulation efficiency; LC, loading capacity; MD, mean diameter; PDI, polydispersity index; ZP, zeta potential; RP, residual PVA.

mean particle size of SLN was $156.33 \pm 7.51 \mathrm{~nm}$ with PDI $0.26 \pm 0.04$ and zeta potential $-22.70 \pm 1.40 \mathrm{mV}$. The loading capacity and encapsulation efficiency of SLN were $4.40 \% \pm 0.16 \%$ and $41.36 \% \pm 1.50 \%$. The residual PVA associated with the SLN was $1.28 \% \pm 0.12 \%$ (Table 1).

\section{In vitro release}

In vitro release curve of ofloxacin-SLN exhibited a biphasic pattern (Figure 2). There was a fast phase with about $34.33 \%$ drug released within the initial 24 hours, followed by a slow and sustained phase. The amount of cumulated drug over 120 hours was $49.15 \%$. In the ofloxacin solution control, the release was about $92.45 \%$ within 2 hours and reached $100 \%$ by 24 hours.

\section{In vitro antibacterial activity}

In vitro antibacterial activity studies showed that the MIC of the native ofloxacin increased with the increase of incubation time. The released ofloxacin had the same MIC as the native ofloxacin at all time points. At 12 hours ofloxacin-SLN had the same MIC as native ofloxacin, but later ofloxacin-SLN had a lower MIC than native ofloxacin (Table 2).

\section{Pharmacokinetics}

After oral administration of ofloxacin solution, plasma drug concentration reached a peak level of $1.2 \mu \mathrm{g} / \mathrm{mL}$ at 0.60 hours, then slowly decreased (Figure 3). The plasma drug level dropped to $0.08 \mu \mathrm{g} / \mathrm{mL}$ by 12 hours and was undetectable

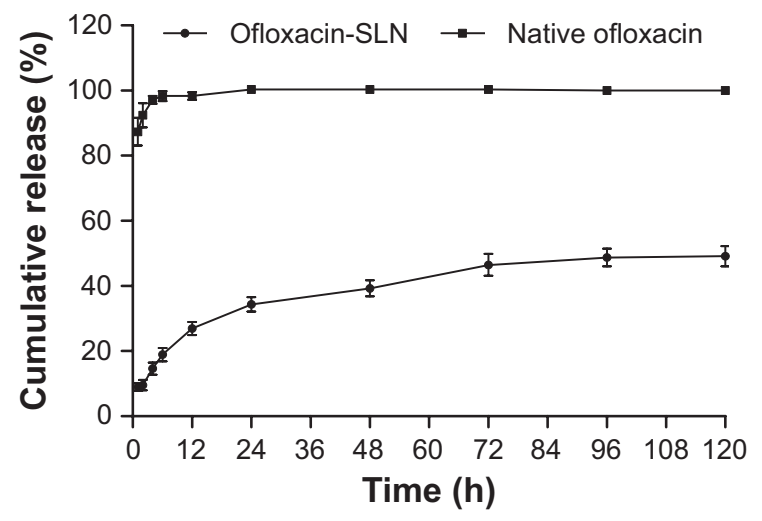

Figure 2 In vitro release of native ofloxacin solution and ofloxacin-loaded solid lipid nanoparticles $(S L N)($ mean $\pm S D, n=3)$. by 18 hours. In the SLN groups, ofloxacin reached a significantly higher peak concentration of $3.64 \mu \mathrm{g} / \mathrm{mL}$ at 0.33 hours, then decreased sharply to the same levels of native drug 1 hour post-administration. Although the plasma drug concentration similarly decreased to $0.09 \mu \mathrm{g} / \mathrm{mL}$ at 12 hours, the concentration was maintained over $0.08 \mu \mathrm{g} / \mathrm{mL}$ for up to 48 hours in the nanoparticles groups.

The $\mathrm{AUC}_{0-\infty}$ value of ofloxacin-loaded SLN was 2.27-fold higher than those obtained with the ofloxacin solution (Table 3). The elimination half-life $\left(\mathrm{T}_{1 / 2} \mathrm{el}\right)$ and the mean residence time (MRT) were also enhanced significantly compared with the ofloxacin solution.

\section{In vivo antibacterial efficacy}

The mortality rates of mice infected with the 3 inoculations $\left(3 \times 10^{9}, 6 \times 10^{9}\right.$, and $\left.12 \times 10^{9} \mathrm{cfu}\right)$ were $60 \%, 100 \%$, and $100 \%$, respectively (Figure 4 ). The inoculation of $6 \times 10^{9} \mathrm{cfu} / \mathrm{mL}$ was selected as the minimum lethal inoculation size and used for the subsequent treatment studies.

Figure 5 shows the survival rates of infected mice treated with ofloxacin-loaded SLN and ofloxacin solution. The survival curves show that SLN is superior to ofloxacin solution. The proportion of survivors for $5 \mathrm{mg} / \mathrm{kg}, 10 \mathrm{mg} / \mathrm{kg}$, and $20 \mathrm{mg} / \mathrm{kg}$ doses in ofloxacin-loaded SLN groups were $3 / 10(30 \%), 5 / 10(50 \%)$, and $6 / 10(60 \%)$ over the observed period, respectively, compared with $0 / 10(0 \%), 3 / 10(30 \%)$, and $3 / 10(30 \%)$ in ofloxacin solution groups.

\section{Discussion}

In this study, ofloxacin-loaded SLN were prepared by a hot homogenization and ultrasonication method. In this method, the choice of lipid is crucial in the formulation design. ${ }^{29}$ Lipids must be selected based on their ability to solubilize the drug. ${ }^{29}$

Table 2 Minimal inhibitory concentrations (MIC) of ofloxacin $(n=3)$

\begin{tabular}{lllll}
\hline Ofloxacin & \multicolumn{4}{l}{ MIC $(\mu \mathrm{g} / \mathbf{m L})$} \\
\cline { 2 - 5 } & $\mathbf{1 2} \mathbf{~ h}$ & $\mathbf{2 4} \mathbf{~ h}$ & $\mathbf{3 6} \mathbf{~}$ & $\mathbf{4 8} \mathbf{~}$ \\
\hline Native & 0.2 & 0.4 & 0.5 & 0.5 \\
Released & 0.2 & 0.4 & 0.5 & 0.5 \\
SLN-loaded & 0.2 & 0.3 & 0.3 & 0.3 \\
\hline
\end{tabular}

Abbreviation: SLN, solid lipid nanoparticles. 
A

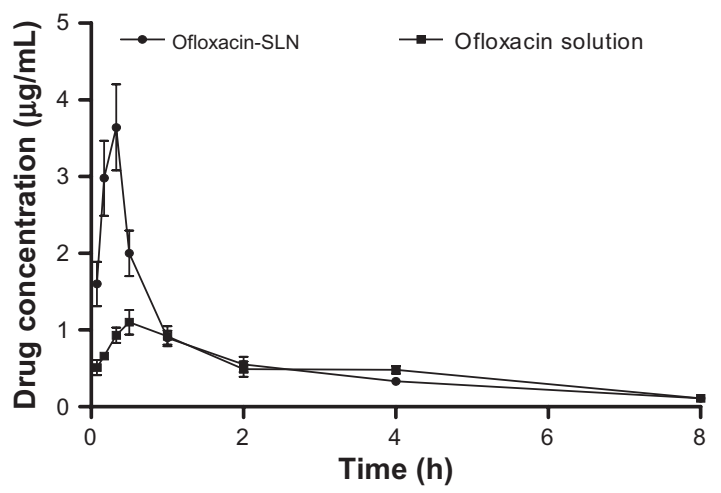

B

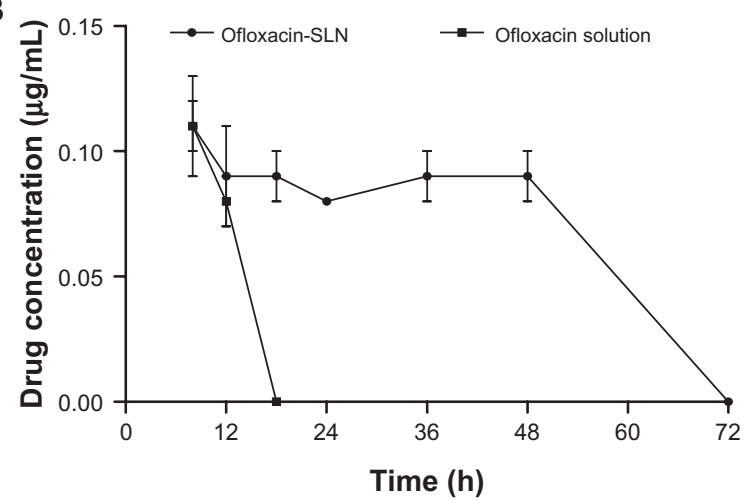

Figure 3 Plasma ofloxacin concentration-time curves after oral administration of ofloxacin-loaded solid lipid nanoparticles (SLN) and ofloxacin solution in mice (mean \pm SD, $\mathrm{n}=5$ ). A) within 8 hours; B) from 8 to 72 hours.

Palmitic acid was selected because of its high dissolution of ofloxacin, although other lipids such as hydrogenated castor oil had better characteristics used as lipid matrices to prepare SLN. ${ }^{23,27}$ Hydrogenated castor oil-SLN was an effective nanoparticle system for controlled release and enhancement of pharmacological activities of encapsulated drugs, ${ }^{23,27}$ but ofloxacin hardly dissolved in the melted lipid.

Ofloxacin had good retention in the drug-lipid mixture once it was dissolved. The drug did not crystallize from the melted palmitic acid even when the temperature of the mixture decreased from $150^{\circ} \mathrm{C}$ to $85^{\circ} \mathrm{C}$. Therefore, the ofloxacin could stay dispersed in the melted lipid during the emulsification process, and the status was maintained during the fast cooling of the emulsion. Part of the drug diffused into the PVA solution, resulting in lower drug encapsulation efficiency and loading capacity. ${ }^{19}$ In addition, the drug maintained its stability and antibacterial activity because the temperature in the preparation did not exceed the melting point of ofloxacin $\left(270\right.$ to $\left.275^{\circ} \mathrm{C}\right)$. The preparation resulted in consistent nanoparticles of $156.33 \pm 7.51 \mathrm{~nm}$ with narrow size distribution. The small size of nanoparticles is favorable for improving the per oral performance of incorporated poorly soluble drugs. ${ }^{30}$

The initial fast release of the drug could be due to desorption and diffusion of ofloxacin accumulated at the oilwater interface and in the outer shell of nanoparticles. ${ }^{17,19,23,24}$ The initial release should be sufficiently rapid to ensure that the therapeutic drug levels are achieved in a timely manner in vivo. The subsequent slow release is mainly due to the slow diffusion of drug molecules through the lipid matrix of the nanoparticles. ${ }^{17-19}$ Slow drug release will contribute to maintaining the effective therapeutic drug concentrations.

In vitro antibacterial activity studies showed that the MIC of native ofloxacin increased with the increase of incubation time. This could be explained by the fact that the native drug gradually loses its effect and bacteria that escaped drug action can multiply rapidly. ${ }^{31} \mathrm{SLN}$ enhanced the antibacterial efficacy of ofloxacin against $S$. aureus evaluated by MIC, possibly because of better penetration of nanoparticles into the bacterial cells and better delivery of drug to its site of action. ${ }^{30,32}$ Sustained release of nanoparticles could also enhance the antibacterial efficacy of antibiotics. ${ }^{24,31}$

SLN significantly increased the bioavailability and extended the systemic circulation of ofloxacin. This could be attributed to a number of reasons. Because of their large surface area, SLN could improve the dissolution rate and level of drug in the presence of gastrointestinal fluids, ${ }^{29,30}$ leading to shorter $\mathrm{T}_{\text {max }}$ and higher peak plasma ofloxacin concentration. In addition, SLN may adhere to the gastrointestinal tract wall or enter the intervillar spaces because of their small particle size, thus increasing their residence time in the gastrointestinal tract. ${ }^{33,34}$ Moreover, nanoparticles could protect the drug from chemical and enzymatic degradation and gradually release drug from the

Table 3 Pharmacokinetic parameters of ofloxacin after oral administration in mice (mean $\pm S D, n=5$ )

\begin{tabular}{lllllll}
\hline Formulation & MRT (h) & AUC $_{0-\infty}(\mathbf{m g} / \mathbf{h} / \mathbf{L})$ & $\mathbf{C}_{\max }(\mu \mathrm{g} / \mathrm{mL})$ & $\mathbf{T}_{\max }(\mathbf{h})$ & $\mathbf{T}_{1 / 2}$ ab (h) & $\mathbf{T}_{1 / 2} \mathbf{e l}(\mathbf{h})$ \\
\hline SLN & $43.44 \pm 13.36^{\mathrm{a}}$ & $12.24 \pm 1.50^{\mathrm{a}}$ & $3.64 \pm 0.48^{\mathrm{a}}$ & $0.33^{\mathrm{a}}$ & $0.06 \pm 0.03^{\mathrm{a}}$ & $28.72 \pm 9.66^{\mathrm{a}}$ \\
Solution & $10.50 \pm 2.81$ & $5.39 \pm 0.45$ & $1.12 \pm 0.12$ & $0.60 \pm 0.22$ & $0.17 \pm 0.05$ & $9.10 \pm 1.63$ \\
\hline
\end{tabular}

Notes: ${ }^{a}$ Statistical significance compared with solution, $P<0.05$.

Abbreviations: MRT, mean residence time; $\mathrm{AUC}_{0-\infty}$, area under the concentration-time curve from zero to infinity; $\mathrm{C}_{\max }$, maximal ofloxacin concentration in plasma; $\mathrm{T}_{\max }$, time to reach $\mathrm{C}_{\max } ; \mathrm{T}_{1 / 2}$ ab, absorption half-life; $\mathrm{T}_{1 / 2}$ el, elimination half-life. 


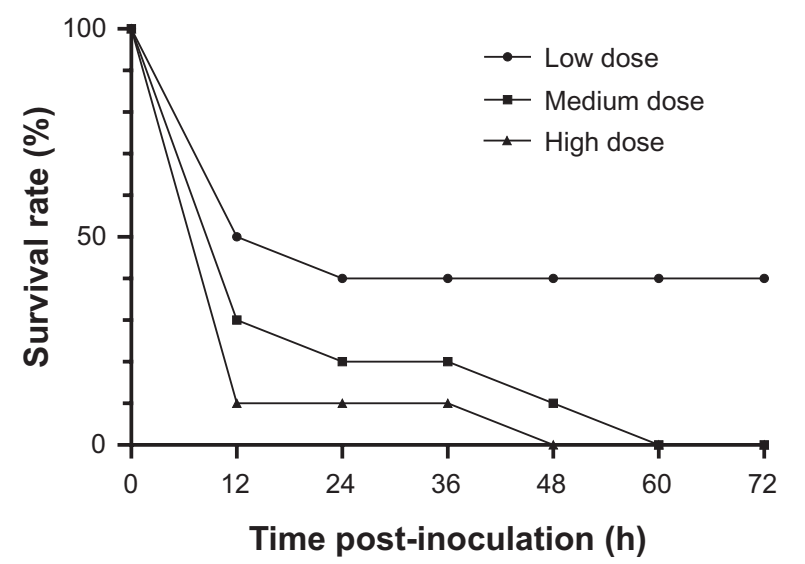

Figure 4 Percentage survival of mice infected with different inoculations of $S$. aureus (CCVCC2248). Inoculations: low dose: $3 \times 10^{9} \mathrm{cfu} / \mathrm{mL}$; medium dose: $6 \times 10^{9} \mathrm{cfu} / \mathrm{mL}$; high dose: $12 \times 10^{9} \mathrm{cfu} / \mathrm{mL}$.

lipid matrix into blood ${ }^{27}$ resulting in a several-fold increase in MRT compared with native drug.

Although the sustained-release performance of the ofloxacin-loaded SLN was not as good as that of the other drugloaded SLN in our previous studies,,$^{23,25,27}$ the concentration of $0.09 \mu \mathrm{g} / \mathrm{mL}$ was therapeutically effective for many common pathogens. ${ }^{2,4,9,35}$

A

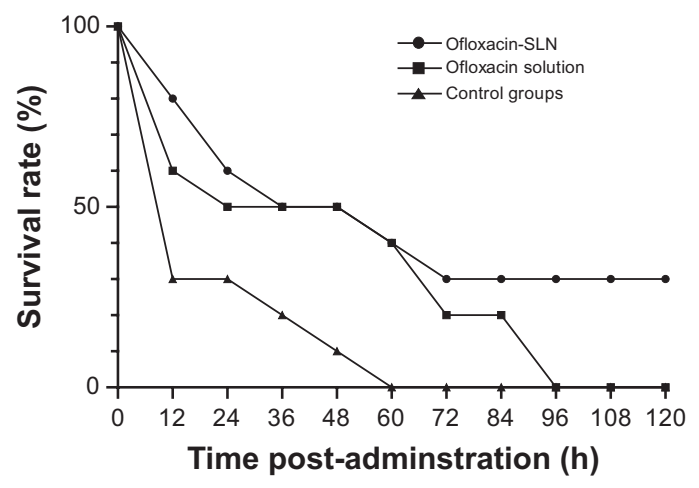

The determination of survivorship in an experimental mouse infection model remains a primary model for evaluation of efficacy of antimicrobial agents. ${ }^{36}$ The higher proportions of survivors indicate that SLN enhanced the in vivo antimicrobial efficacy of ofloxacin. Previous research suggests that the therapeutic activities of fluoroquinolones in experimental infections are related to their pharmacokinetic behavior. ${ }^{37,38}$ Ofloxacin exhibits concentration-dependent antibacterial activity. ${ }^{39}$ The higher AUC and peak plasma concentrations $\left(\mathrm{C}_{\max }\right)$ can improve its bactericidal efficacy. The sustained release could result in better in vivo efficacy. Although the sustained plasma concentration was lower than the MIC of ofloxacin against S. aureus, ofloxacin penetrates efficiently throughout the body, with concentrations in tissues and body fluids reported to be higher than those in plasma. ${ }^{2,3,9,40}$ Besides, the long post-antibiotic effect of ofloxacin can prevent bacteria regrowth even when plasma and tissue concentrations decrease below MIC. ${ }^{39,41}$ The interaction of SLN with bacteria might also enhance the in vivo bactericidal efficiency of ofloxacin, but further experiments need to be done to elucidate this effect.

B

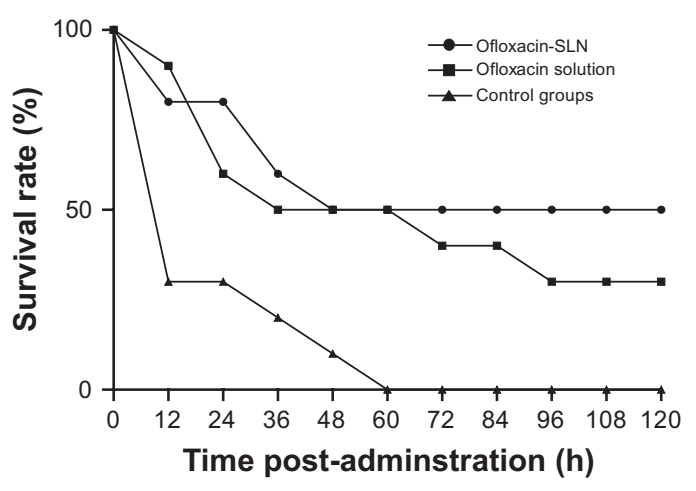

C

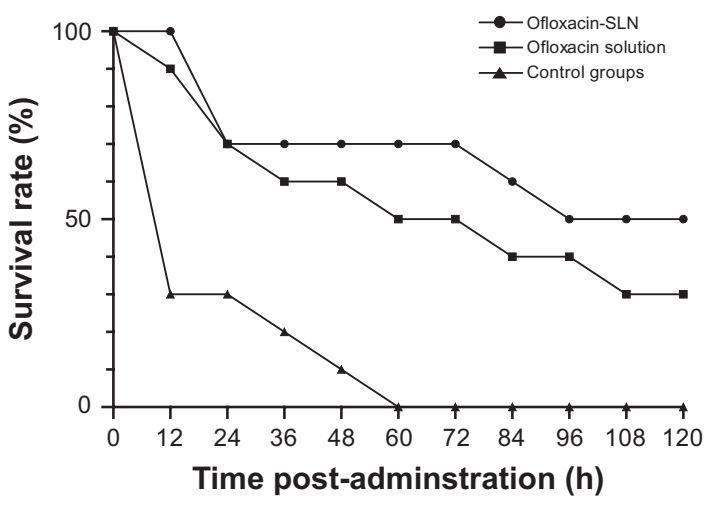

Figure 5 Percentage survival of lethal dose infection mice treated with a single dose of ofloxacin-loaded solid lipid nanoparticles (SLN) or ofloxacin solution; A) 5 mg/kg; B) $10 \mathrm{mg} / \mathrm{kg}$; C) $20 \mathrm{mg} / \mathrm{kg}$. Ten mice were used for each treatment group. 


\section{Conclusion}

Ofloxacin was successfully incorporated into palmitic acidSLN by a hot homogenization and ultrasonication method. SLN had a sustained-release effect and enhanced antibacterial activity against $S$. aureus in vitro. SLN significantly improved the bioavailability, systematic circulation time, and in vivo efficacy of ofloxacin. The nanoparticle system would be an effective vehicle for oral delivery of ofloxacin to improve its pharmacological activity.

\section{Acknowledgments}

This work was supported by the Innovation Fund for Graduate Student of China Agricultural University (kycx2010051).

\section{Disclosure}

The authors declare no conflicts of interest.

\section{References}

1. Todd PA, Faulds D. Ofloxacin. A reappraisal of its antimicrobial activity, pharmacology and therapeutic use. Drugs. 1991;42:825-876.

2. Saito A, Sawatari K, Fukuda Y, et al. Susceptibility of Legionella pneumophila to ofloxacin in vitro and in experimental Legionella pneumonia in guinea pigs. Antimicrob Agents Chemother. 1985;28: $15-20$.

3. Monk JP, Campoli-Richards DM. Ofloxacin. A review of its antibacterial activity, pharmacokinetic properties and therapeutic use. Drugs. 1987;33:346-391.

4. Grüneberg RN, Felmingham D, O'Hare MD, et al. The comparative invitro activity of ofloxacin. J Antimicrob Chemother. 1988;22 Suppl C: 9-19.

5. Martinez M, McDermott P, Walker R. Pharmacology of the fluoroquinolones: A perspective for the use in domestic animals. Vet $J$. 2006;172:10-28.

6. Okonogi S, Oguchi T, Yonemochi E, Puttipipatkhachorn S, Yamamoto K. Improved dissolution of ofloxacin via solid dispersion. Int $J$ Pharm. 1997:156:175-180.

7. Agro AS, Garner ET, Wright JW, de Escobar C, Villeda B, Seidlin M. Clinical trial of ototopical ofloxacin for treatment of chronic suppurative otitis media. Clin Ther. 1998;20:744-759.

8. Gentry LO, Rodriguez-Gomez G. Ofloxacin versus parenteral therapy for chronic osteomyelitis. Antimicrob Agents Chemother. 1991;35: $538-541$.

9. Wang F, Gu XJ, Zhang MF, Tai TY. Treatment of typhoid fever with ofloxacin. J Antimicrob Chemother. 1989;23:785-788.

10. Marier JF, Ducharme MP, DiMarco M, et al. Two open-label, randomized, crossover studies assessing the bioequivalence of ofloxacin administered as immediateand extended-release formulations in healthy subjects. Clin Ther. 2006;28:2070-2080.

11. Yew WW, Kwan SY, Ma WK, Khin MA, Chan PY. In-vitro activity of ofloxacin against Mycobacterium tuberculosis and its clinical efficacy in multiply resistant pulmonary tuberculosis. JAntimicrob Chemother. 1990;26:227-236.

12. Chavanpatil M, Jain P, Chaudhari S, Shear R, Vavia P. Development of sustained release gastroretentive drug delivery system for ofloxacin: In vitro and in vivo evaluation. Int J Pharm. 2005;304:178-184.

13. Cui Y, Zhang Y, Tang X. In vitro and in vivo evaluation of ofloxacin sustained release pellets. Int J Pharm. 2008;360:47-52.

14. Chavanpatil MD, Jain P, Chaudhari S, Shear R, Vavia PR. Novel sustained release, swellable and bioadhesive gastroretentive drug delivery system for ofloxacin. Int J Pharm. 2006;316:86-92.
15. Furneri PM, Fresta M, Puglisi G, Tempera G. Ofloxacin-loaded liposomes: in vitro activity and drug accumulation in bacteria. Antimicrob Agents Chemother. 2000;44:2458-2464.

16. Hwang SM, Kim DD, Chung SJ, Shim CK. Delivery of ofloxacin to the lung and alveolar macrophages via hyaluronan microspheres for the treatment of tuberculosis. J Control Release. 2008;129:100-106.

17. Xie SY, Wang SL, Zhao BK, Han C, Wang M, Zhou WZ. Effect of PLGA as a polymeric emulsifer on preparation of hydrophilic proteinloaded solid lipid nanoparticles. Colloids Surf B Biointerfaces. 2008; 67:199-204.

18. Mehnert W, Mäder K. Solid lipid nanoparticles: production, characterization and applications. Adv Drug Deliver Rev. 2001;47:165-196.

19. Müller RH, Mäder K, Gohla S. Solid lipid nanoparticles (SLN) for controlled drug delivery - a review of the state of the art. Eur J Pharm Biopharm. 2000;50:161-177.

20. Zhang ZW, Bu HH, Gao ZW, Huang Y, Gao F, Li YP. The characteristics and mechanism of simvastatin loaded lipid nanoparticles to increase oral bioavailability in rats. Int J Pharm. 2010;394:147-153.

21. Müller RH, Runge S, Ravelli V, Mehnert W, Thunemann AF, Souto EB. Oral bioavailability of cyclosporine: Solid lipid nanoparticles (SLN $\left.{ }^{\circledR}\right)$ versus drug nanocrystals. Int J Pharm. 2006;317:82-89.

22. Pandey R, Sharma S, Khuller GK. Oral solid lipid nanoparticle-based antitubercular chemotherapy. Tuberculosis. 2005;85:415-420.

23. Han C, Qi CM, Zhao BK, et al. Hydrogenated castor oil nanoparticles as carriers for the subcutaneous administration of tilmicosin: in vitro and in vivo studies. J Vet Pharmacol Ther. 2009;32:116-123.

24. Wang XF, Zhang SL, Zhu LY, et al. Enhancement of antibacterial activity of tilmicosin against Staphylococcus aureus by solid lipid nanoparticles in vitro and in vivo. Vet J. 2011. In press.

25. Xie SY, Zhu LY, Dong Z, et al. Preparation, characterization and pharmacokinetics of enrofloxacin-loaded solid lipid nanoparticles: influences of fatty acids. Colloids Surf B Biointerfaces. 2011; doi:10.1016/j.colsurfb.2010.12.014.

26. DeMerlis CC, Schoneker DR. Review of the oral toxicity of polyvinyl alcohol (PVA). Food Chem Toxicol. 2003;41:319-326.

27. Xie SY, Pan BL, Wang M. Formulation, characterization and pharmacokinetics of praziquantel-loaded hydrogenated castor oil solid lipid nanoparticles. Nanomedicine. 2010;5:693-701.

28. Clinical and Laboratory Standards Institute. Development of In Vitro Susceptibility Testing Criteria and Quality Control Parameters; Approved Standard. 2nd ed. Clinical and Laboratory Standards Institute, Wayne, PA; 2001.

29. Chakraborty S, Shukla D, Mishra B, Singh S. Lipid - An emerging platform for oral delivery of drugs with poor bioavailability. Eur $J$ Pharm Biopharm. 2009;73:1-15.

30. Luo YF, Chen DW, Ren LX, Zhao XL, Qin J. Solid lipid nanoparticles for enhancing vinpocetine's oral bioavailability. $J$ Control Release. 2006;114:53-59.

31. Misra R, Acharya S, Dilnawaz F, Sahoo SK. Sustained antibacterial activity of doxycycline-loaded poly(D,L-lactide-co-glycolide) and poly( $\varepsilon$-caprolactone) nanoparticles. Nanomedicine. 2009;5: 519-530.

32. Esmaeili F, Hosseini-Nasra M, Rad-Malekshahia M, Samadi N, Atyabi F, Dinarvand R. Preparation and antibacterial activity evaluation of rifampicin-loaded poly lactide-co-glycolide nanoparticles. Nanomedicine. 2007;3:161-167.

33. Duchêne D, Ponchel G. Bioadhesion of solid oral dosage forms, why and how? Eur J Pharm Biopharm. 1997;44:15-23.

34. Vasir JK, Tambwekar K, Garg S. Bioadhesive microspheres as a controlled drug delivery system. Int J Pharm. 2003;255:13-32.

35. Hoogkamp-Korstanje JAA. In-vitro activities of ciprofloxacin, levofloxacin, lomefloxacin, ofloxacin, pefloxacin, sparfloxacin and trovafloxacin against Gram-positive and Gram-negative pathogens from respiratory tract infections. J Antimicrob Chemother. 1997;40: 427-431.

36. Zal O, O'Reilly T. Animal models in the evaluation of antimicrobial agents. Antimicrob Agents Chemother. 1991;35:1527-1531. 
37. Craig WA. Pharmacokinetic:pharmacodynamic parameters: Rationale for antibacterial dosing of mice and men. Clin Infect Dis. 1998;26:1-12.

38. Fu KP, Lafredo SC, Foleno B, et al. In vitro and in vivo antibacterial activities of levofloxacin (L-ofloxacin), an optically active ofloxacin. Antimicrob Agents Chemother. 1992;36:860-866.

39. Lode H, Borner K, Koeppe P. Pharmacodynamics of fluoroquinolones. Clin Infect Dis. 1998;27:33-39.
40. Wise R, Lockley MR. The pharmacokinetics of ofloxacin and a review of its tissue penetration. J Antimicrob Chemother. 1988;22 Suppl C: 59-64.

41. Howard BMA, Pinney RJ, Smith JT. Post-antibiotic effects of ofloxacin on Escherichia coli, Klebsiella pneumoniae, Staphylococcusaureus, and Streptococcus pyogenes. Chemotherapy. 1993;39:265-271.
International Journal of Nanomedicine

\section{Publish your work in this journal}

The International Journal of Nanomedicine is an international, peerreviewed journal focusing on the application of nanotechnology in diagnostics, therapeutics, and drug delivery systems throughout the biomedical field. This journal is indexed on PubMed Central,

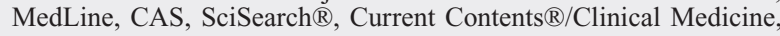

\section{Dovepress}

Journal Citation Reports/Science Edition, EMBase, Scopus and the Elsevier Bibliographic databases. The manuscript management system is completely online and includes a very quick and fair peer-review system, which is all easy to use. Visit http://www.dovepress.com/ testimonials.php to read real quotes from published authors.

Submit your manuscript here: http://www.dovepress.com/international-journal-of-nanomedicine-journal 